\title{
Um elo entre letramento crítico digital e o ensino de inglês para a formação de leitores
}

\section{A link between critical digital literacy and English teaching for the development of the readers}

Nelza Mara Pallu ${ }^{1}$

Professora Doutora em Letras da Universidade Estadual do Oeste do Paraná UNIOESTE; Professora do Programa de Pós-Graduação em Desenvolvimento Rura Sustentável - linha de pesquisa: Inovaçōes Socio-tecnológicas e Açăo Extensionista da UNIOESTE; Pesquisadora do Grupo de Pesquisa Poeticas do Imaginário e Memóría CNPq, Bolsista Programa Capes/PIBIDInglês do Campus de Marechal Cândido Rondon da UNIOESTE.

E-mail: nelza.pallu@unioste.br
RESUMO: Este artigo apresenta uma experiência realizada com o objetivo de enriquecer a formação de professores de inglês, de modo que eles interagissem de forma mais contundente na formação de leitores, propiciando condições significativas à aprendizagem. 0 trabalho foi proposto através de um projeto específico, denominado Projeto Literamento nas Aulas de Inglês (PLAI), inserido no Programa Institucional de Bolsa de Iniciação à Docência - PIBID Letras/Inglês e aplicado em turmas do Ensino Fundamental em uma escola da Rede Estadual de Ensino do Paraná. A metodologia adotada privilegiou a integração dos estudos do Letramento Crítico, do Letramento Digital, da Literatura e das Abordagens Discursivas para o ensino de Línguas Estrangeiras. Os resultados demonstraram que esta composição metodológica multifacetada proporcionou a construção de atividades inovadoras nas aulas de inglês e promoveu o interesse e a motivação da aprendizagem, favorecendo a inserção de todos os participantes do projeto no mundo dos letramentos. Os dados revelaram ainda que o uso de tecnologias e da literatura nas aulas de inglês favoreceu o processo de formação de leitores. Contudo, para o desafio do letramento dos sujeitos é necessário investir na formação inicial e continuada de professores nas universidades em todas as áreas do conhecimento. 0 programa PIBID pode ser o local propício para junção destes esforços.

PALAVRAS-CHAVE: Formação de Professores de Inglês; Leitura e Literatura; Letramento Crítico Digital.

ABSTRACT: This article presents a project called (PLAI - Projeto Literamento nas Aulas de Inglês) designed with the aim of improving the English Teachers' Training process in order to better interact with the training of readers, by offering meaningful conditions to the English learning process. The work was developed through the PIBID Program (Programa de Bolsa de Iniciação à Docência) and applied in the Fundamental Schooling level in a public school in the State of Paraná. The basic approach was under the integration of the studies of Literature, Critical and Digital Literacy, and the Language Teaching Theories. The results demonstrated that this multifaceted methodological composition favored innovative activities for the English classes, and hence, promoted the interest and motivation of the students supporting the inclusion of the participants of the Project in the literacy world. Although the data revealed that the use of technology and literature favored the reading development, in order to empower the process of reading, further effort is necessary investing firstly in the training teachers' in the universities in all fields of knowledge. The PIBID program can be the place for gathering these conditions.

KEYwords: English Teacher Training; Reading and Literature; Critical and Digital Literacy. 


\section{Introdução}

tarefa de contribuir para o letramento ${ }^{1}$ dos alunos das escolas regulares brasileiras tem sido fonte constante de debates, não somente nas áreas exclusivas dos estudos da linguagem, como também nos diferentes contextos advindos das variadas áreas do conhecimento. Contudo, mesmo que haja uma concentração de esforços visando a uma melhoria no nível da produção e do consumo de textos da população em geral, ainda há muitos desafios a serem enfrentados no que se refere à formação de leitores.

Considerando o caráter polissêmico diante de variadas interpretações para o fenômeno do letramento (desde a conhecida referência ao antigo uso como binômio ou contraposição da palavra alfabetização à sua pluralização "letramentos", utilizada para dar ênfase à renovação do termo), é fundamental entender o que este conceito representa, ou seja, do que estamos falando quando utilizamos o termo letramento.

Neste contexto, pensando nas dificuldades dos sujeitos, quando postos ao ato de ler e compreender textos, nas situações em que lhes é requerido o enfrentamento perante a leitura e a compreensão de diferentes gêneros discursivos, ainda são muito evidentes os exemplos que podem ilustrar essa situação. Destacam-se aqui os obstáculos enfrentados pelos alunos, em geral, na realização de provas de avaliação da educação brasileira, como no ENEM. O balanço dos resultados das provas de redação divulgados pelo $\mathrm{MEC}^{2}$ evidencia as principais dificuldades dos participantes, destacandose dentre elas, a apresentação de textos insuficientes, o não atendimento ao tipo textual e a fuga ao tema, conforme ratificam os seguintes dados:

${ }^{1}$ Letramento: capacidade de ler e produzir significações (FREIRE, 1992), levando-se em consideração os aspectos sociais da linguagem (KLEIMAN, 2007).

Fonte dos dados: <http://portal.mec.gov.br/indexphp?option=com_docman\&view=download\&alias= 16869-apresentacao-coletiva-enem-13012015\&Itemid=30192>. Acesso em: 28 jul. 2016. a) do total de 6.193 .565 participantes, $8,55 \%$ tiveram suas provas anuladas; b) somente $0,0040 \%$ obtiveram a nota máxima (1000); c) a maior pontuação obtida (entre 501 e 600 ) foi de $24,46 \%$.

Esta realidade tem impulsionado os profissionais da educação - e não somente os professores de português - a assumirem o compromisso de fortalecer as relações com a produção da escrita e da leitura. No entanto, muitos professores, mesmo que imbuídos do interesse de contribuir para esta tarefa, muitas vezes se encontram com dúvidas em como conduzir sua prática pedagógica. Contribuir efetivamente para a superação dos desafios do letramento, no sentido de auxiliar os alunos a ler, interpretar e escrever para que assim possam expressar suas ideias e se posicionarem nas situações vivenciadas, é uma tarefa complexa. Por isso, buscar apoio teórico pertinente, desenvolver estratégias e planos de ação são medidas importantes para auxiliar os profissionais interessados pela produção de conhecimentos multifacetados que visem à melhoria da educação em geral.

$\mathrm{Na}$ área do ensino de línguas estrangeiras, esta questão também tem sido debatida nas últimas décadas, quando as abordagens de ensino passaram a ser respaldadas em concepções discursivas ${ }^{3}$ (DIAS, 2005; MACHADO, 2003; MENEZES DE SOUZA, 2011; PIMENTA, 2005). Considerando-se que no ensino de língua estrangeira se recomenda que as relações com a cultura, com o sujeito e com a identidade sejam contempladas (PARANÁ, 2008) não há como deixar que as questões de leitura na própria língua materna sejam ignoradas. Ao contrário, privilegia-se que as competências e os conhecimentos produzidos no ensino de português, que compõem os conhecimentos prévios do aluno, sejam utilizados em favor da aquisição

${ }^{3}$ As concepções discursivas para o ensino de Línguas concebem a língua como discurso; e o discurso é entendidocomoumconjuntode onunciadospertencentesacampos diferentes, mascomp rocedime entemuns de produção enum mesmo sistema de formaça A língua é, pois, um sistema de construção conuns de de enunciados (PALLU, 2013, p. 71). 
de um novo idioma. No caso do ensino da língua inglesa, área de interesse neste estudo, há que se notar um interesse crescente pela participação ativa na formação de leitores, conjuntamente aos investimentos efetuados pelos profissionais de outras áreas em um movimento pedagógico interdisciplinar.

Levando-se em consideração os desafios da leitura, este artigo apresenta, assim, um projeto planejado, desenvolvido e executado no ano de 2014 por um grupo composto por profissionais do Curso de Letras da Universidade Estadual do Oeste do Paraná-Unioeste, participantes do Programa Institucional de Bolsa de Iniciação à Docência - PIBID ${ }^{4}$ de Letras/Inglês, que tem como objetivo investir na formação de professores de inglês para interagirem com maior ênfase na motivação da leitura nas aulas de inglês.

O planejamento das ações do projeto foi desenvolvido nos estabelecimentos da Unioeste e sua aplicação ocorreu no espaço das aulas de inglês no ensino fundamental de uma escola pública. Neste delineamento, o projeto buscou atender aos seguintes propósitos: 1) contribuir para a formação (continuada e inicial) de professores de inglês; 2) motivar os alunos da escola participante à aprendizagem de inglês; 3) fomentar o uso de tecnologias no projeto; 4) enriquecer a formação de leitores.

O embasamento teórico deste trabalho, explanado no decorrer do artigo, é composto por um conjunto de concepções integradas (letramento crítico, letramento digital e literamento ${ }^{5}$ ), visando englobar o uso de textos literários e diferentes tecnologias para o incentivo à leitura nas aulas de inglês. Esta experiência é entendida como um projeto de leitura de mundo conectado aos

${ }^{4}$ PIBID: Programa subsidiado pela CAPES que objetiva a valorização da formação de professores para a educação básica. Disponível em: <http://www.capes.gov.br/educacao-basica/capesPIBID>. Acesso em: 11 abr. 2016

5 Literamento: Termo criado pela coordenadora do PLAI/PIBID para denominar a interface dos conhecimentos produzidos pela integração entre estudos literários, linguísticos, tecnológicos e cinematográficos (PALLU, 2012). novos formatos culturais de utilizar as linguagens na comunicação e para a construção de sentidos aos usuários.

A experiência com o projeto denominado de Projeto Literamento nas Aulas de Inglês (doravante $\mathrm{PLAI}^{6}$ ) é relatada nas seções seguintes, visando demonstrar que o uso planejado de tecnologias na formação de leitores pode contribuir de maneira positiva aos estudos de línguas estrangeiras e à formação de professores.

\section{0 letramento crítico digital na formação de professores de inglês}

Contemplar a formação de professores de inglês sob o prisma do reconhecimento de uma língua responsável pela propagação da informação internacional, em diferentes esferas, representa um grande desafio nos dias atuais. A área da Linguística Aplicada (LA) tem dedicado seus trabalhos voltados para esta questão nos últimos anos, abrindo os debates para o ensino de inglês como uma língua franca ${ }^{7}$ (JENKINS, 2008) com o objetivo de tornar a aprendizagem do inglês democrática e significativa aos alunos, especialmente aos falantes e usuários não nativos (EL KADRI, 2011; PALLU, 2013).

Contudo, é possível perceber que, embora haja uma grande quantidade de pesquisas que têm se ocupado com o fenômeno do uso do inglês para a comunicação internacional e o entretenimento, os cursos de Letras ainda não adequaram seus currículos a esta realidade (EL KADRI, 2011), continuando

6 PLAI: Projeto Literamento nas Aulas de Inglês desenvolvido pelo Programa Institucional de Bolsa de Iniciação à Docência (PIBID de Letras/Inglês), da Unioeste no campus de Marechal Cândido Rondon (2014-2015).

7 Inglês como Língua Franca: termo acadêmico utilizado para ressaltar e estudar o crescente fenômeno de usuários falantes não nativos do inglês no mundo visando sua democratização (PALLU, 2013). 
a formar professores para o ensino de inglês como uma língua estrangeira com oportunidades limitadas de uso aos alunos.

Considerando que esta temática abrange inúmeras questões relacionadas à concepção de ensino de línguas estrangeiras, este texto faz um recorte direcionando para as possíveis contribuições presentes na esfera do letramento crítico e do letramento digital para a formação de professores de inglês. A denominação letramento crítico digital é entendida, neste texto, como uma concepção abrangente na qual se considera o contexto sociocultural, histórico e político para a utilização das tecnologias dos sujeitos e não simplesmente como um aparato tecnológico. Ou seja, concebe-se o "letramento digital como prática social culturalmente constituída" (FREITAS, 2010, p. 338).

No PLAI, esta prática é realizada pelos seguintes agentes: professoras de inglês em serviço na escola e na universidade que atuam em contextos públicos de ensino (formação continuada); acadêmicos oriundos de uma universidade estadual, do curso de Letras Português/Inglês (formação acadêmica e inicial); e alunos (ensino fundamental) de uma escola pública regular. Todos reunidos em um projeto promovido por um programa inédito de incentivo à docência na educação brasileira e desenvolvido pela Unioeste em parceria com uma escola pública estadual, na região Oeste do estado Paraná: o Programa PIBID.

Assim, o projeto PLAI, além de buscar promover o aprimoramento do processo de ensino de inglês, foi pautado também pela necessidade de contribuir para o letramento crítico digital na formação dos professores de inglês participantes. Parte-se aqui, do princípio de que para que estes professores sejam considerados letrados digitalmente, é preciso dar condições para que desenvolvam um conhecimento crítico acerca da utilização da tecnologia. Tal habilidade é definida da seguinte maneira por Freitas (op. cit.):
Ser letrado digital inclui, além do conhecimento funcional sobre o uso da tecnologia possibilitada pelo computador, um conhecimento crítico desse uso. Assim, tornar-se digitalmente letrado significa aprender um novo tipo de discurso e, por vezes, assemelha-se até a aprender outra língua (FREITAS 2010, p. 338)

Considerando que para que o professor de inglês possa desenvolver uma prática crítica e significativa, a ideia de aliar os conhecimentos didático-pedagógicos construídos ao longo de sua formação acadêmica ao discurso digital se constitui em uma proposta instigante e desafiadora. Entretanto, esta integração de conhecimentos, embora desejável, necessita estar acompanhada de fundamentos que possam, de fato, nortear as ações dos professores para que seja bem-sucedida. Sendo assim, partimos do pressuposto de que o entendimento do que significa "ter conhecimentos críticos" se torna um elemento fundamental para a composição do letramento digital.

Neste sentido, um movimento teórico que pode auxiliar a concepção da criticidade na formação de professores de línguas estrangeiras se encontra nos fundamentos do Letramento Crítico que se beneficia do pensamento de Foucault (1996) em diálogo com as ideias de Paulo Freire (2005). A composição do Letramento Crítico contempla uma forma de pensar a prática educacional oriunda de vários campos do conhecimento como a educação, a linguística, a sociologia, os estudos políticos, culturais e filosóficos (BRASIL, 2006; JORDÃO, 2007; MARTINEZ, 2007).

Os conceitos apresentados pelo Letramento Crítico sugerem entendimentos importantes para o ensino de inglês, respaldados na noção de língua, discurso e poder, em especial, destacando o entendimento do que vem ser "o sujeito crítico". Jordão (2007) explica-nos esta proposição da seguinte forma: 
O pensamento de Foucault, entretanto, traz uma noção produtiva do poder, da qual as concepções de letramento crítico se beneficiam, sob a perspectiva de que as relações de poder geram resistências potencialmente positivas, que produzem conhecimento nas relações que estabelecem ou modificam entre diferentes formas de conhecimento. Nestas relações atuam os sujeitos críticos, que são capazes de examinar os pressupostos e as implicações das diferentes formas de pensar e agir (JORDÃO, 2007, p. 5).

O Letramento Crítico pode ser entendido como um projeto de leitura de mundo conectado aos novos formatos culturais e digitais de usar a linguagem na contemporaneidade. No processo do ato crítico de ler, a leitura visa reconhecer a linguagem como uma prática sociocultural. A educação, por sua vez, neste entender, tem a tarefa de atuar para o desenvolvimento da consciência crítica dos sujeitos na interpretação de mundo.

Considerando que, na atualidade, os discursos digitais estão sendo produzidos e utilizados em larga escala pelas comunidades, sua introdução na vida escolar necessita de muitos investimentos. Em relação à formação dos professores de inglês, para uma atuação efetiva na relação com o discurso digital de seus alunos, faz-se necessário a busca orientada desta competência. Dentre as variadas formas de diálogos propostos para a educação e para a era digital, a competência no letramento digital parece ser um ponto essencial aos professores. De acordo com Cani (2015), esta competência pode ser construída pelo conjunto das seguintes competências integradas:

a) competência computacional;

b) competência comunicacional;

c) competência multimídia;

d) competência informacional.

A autora explica que a competência computacional se refere aos conhecimentos básicos para o uso do computador, enquanto que a competência comunicacional se refere à expressão oral, gestual e escrita diferenciada presente na comunicação digital, como nas redes sociais, por exemplo. Quanto à competência multimídia, está relacionada à utilização eficaz de diferentes tipos de mídias disponíveis e à compreensão dos textos digitais, como as páginas da web. E por fim, a competência informacional se refere à busca, avaliação e utilização consciente das informações disponíveis, em situações como o conhecimento de sites de busca, os procedimentos seguros para downloads, os critérios de seleção dos chats, juízos de valor para exame e seleção das informações (CANI, 2015).

Desenvolver e explorar estas competências na formação de professores, independentemente da área do conhecimento, é uma prática relevante na era dos chamados nativo-digitais. No caso da formação de professores de inglês, ser um letrado digital é um requisito favorável ao ensino da língua inglesa devido à vasta gama de inputs, ou seja, da presença do idioma em situações de uso na internet e no entretenimento. 0 conjunto das competências integradas, descritas acima, pode ser efetivamente contemplado na formação de professores de línguas, incluindo-se uma quinta competência específica da área de conhecimento: a competência linguística, neste caso, o domínio do inglês.

Concebendo, assim, o uso multifacetado das tecnologias midiáticas como diferentes formas que veiculam a comunicação humana (ou pós-humana ${ }^{8}$ ), o cuidado em utilizar tecnologias no PLAI levou o grupo a buscar uma perspectiva que integrasse não somente a inovação, mas principalmente, a tecnologia educacional. 0 projeto entende que o mero uso de recursos tecnológicos pode se transformar em um recurso educativo genuíno, mas "desde que em interação com o ambiente escolar no processo ensinoaprendizagem” (BRITO, 2008, p. 38).

Era pós-humana: adaptação do termo pós-humano adotado por Santaella (2003) para se referir ao fenômeno de interface ser humano-máquina na era tecnológica. 
Cientes de que somente o uso da tecnologia, por si, não garantiria uma maior significação na aprendizagem de inglês e na formação de leitores, os participantes do projeto buscaram, assim, um trabalho integrado a fundamentações teóricas e conhecimentos práticos desenvolvidos durante a fase de planejamento das atividades e nos encontros de estudos entre o grupo. Os estudos foram subsidiados basicamente considerando o fato de que:

[...] para que as tecnologias não se constituam apenas em uma novidade e não se prestem ao disfarce dos reais problemas existentes, julgamos conveniente que os professores compreendam e aceitem que, atualmente, as mudanças nos proporcionam instrumentos necessários para correspondermos à exigência quantitativa e qualitativa de educação, que esta mesma provoca. 0 que precisamos saber é como reconhecer essas tecnologias e adaptá-las às nossas finalidades educacionais (BRITO, 2008, p. 41).

Na linha de pensamento posta por Brito, acima, definiu-se que, durante a fase de planejamentos do projeto, o grupo dedicaria vários momentos de observação da realidade escolar dos estudantes envolvidos na aplicação do projeto ao longo do período de observação da escola e de momentos de reflexão desta realidade, bem como, durante os encontros semanais realizados na universidade entre os integrantes do PIBID Letras/Inglês. Os períodos de observação e reflexão foram realizados concomitantemente aos estudos teóricos, nos grupos de estudos relacionados ao processo de ensino e aprendizagem de inglês no primeiro trimestre; a aplicação deu-se no segundo trimestre de 2014.

Estes procedimentos são também respaldados por pesquisadores que se dedicam à inserção adequada da tecnologia na educação e nos alertam para a necessidade da visão crítica deste uso, da seguinte maneira:

[...] torna-se imperativo por parte dos educadores o exercício de uma crítica profunda, com vistas a não tornar tais proposições fragmentos didáticos que apenas conferem aos currículos e às suas práticas a aparência de inovação" (SILVA; COLONTONIO, 2014, p. 625, 626).
Assim, o PLAI voltou-se para o uso de tecnologias midiáticas nas aulas de inglês como ferramenta efetiva para a veiculação de informações e produção de conhecimentos linguísticos e culturais, em uma perspectiva de "cultura das mídias", a qual concebe "os casamentos e misturas entre linguagens e meios, misturas essas que funcionam como um multiplicador de mídias" (SANTAELLA, 2003, p. 26).

Essa mescla, que abrange a proliferação das mídias e da cultura virtual (ciberespaço), foi proposta no projeto PLAI, mediante a integração dos estudos advindos dos campos da literatura, da linguística e da tecnologia midiática, em uma abordagem denominada de Literamento, visando uma maior atuação na formação de leitores nas aulas de inglês. As obras literárias (Irmãos Grimm e Harry Potter) foram escolhidas para veiculação e fomento ao processo de leitura nas aulas de inglês, acompanhada do aparato tecnológico (computador, multimídia, vídeos, TV, pen-drive, aparelho de som) tanto em sala de aula como no laboratório de informática da escola. A tecnologia foi utilizada com o intuito de favorecer o interesse dos alunos pelo material literário e, consequentemente, pela aprendizagem de inglês, sempre tendo em vista o objetivo de incentivar a formação de leitores.

Toda a produção em sala de aula, incluindo a elaboração de um Caderno de Atividades, foi registrada e postada no blog ${ }^{9}$ Literamento nas Aulas de Inglês, criado especificamente para tal fim, visando uma maior integração e acompanhamento entre todos os participantes do projeto. Entendendo esta utilização de recursos como "constitutivos de uma cultura das mídias", como aponta Santaella (2003), o aporte tecnológico contemplado no PLAI proporcionou a utilização dos recursos não somente para recepção de mensagens e informações, como também para a produção de materiais didáticos autênticos e diferenciados. Esta formação objetivou, ainda, inserir

${ }^{9}$ Blog Literamento: PIBID Letras de Inglês da Unioeste. Disponível em: <http://pibidinglesmcr.blogspot. com.br/>. Acesso em: 3 abr. 2016. 
no mundo da inclusão tanto os alunos da escola, quanto os estudantes universitários (Pibidianos) participantes do projeto, visando assim, produção e consumo da tecnologia educacional.

Assim, a proposta de interferir na atuação dos professores de inglês participantes do projeto teve como principal objetivo a motivação dos alunos da escola participante à leitura. As aulas de inglês seriam o local desta intervenção e a literatura, o pano de fundo para os investimentos. Cumpre ressaltar, no entanto, que o uso de tecnologias como estratégias para tornar a prática significativa à aprendizagem exigiu muitos esforços, pois o letramento crítico digital representa ainda um desafio a ser enfrentado nas escolas regulares e nas universidades.

\section{0 projeto literamento nas aulas de inglês (PLAI): uma proposta metodológica multifacetada}

O projeto Literamento nas Aulas de Inglês, como o próprio nome sugere, integra diferentes abordagens que se apresentam nos estudos possíveis entre os campos da Literatura/Letramento - LITER (literatura) + AMENTO (letramento), formando um elo entre o letramento crítico digital e o ensino. O PLAI surgiu, primeiramente, pelo interesse e pela preocupação em relação à dificuldade que os alunos apresentam em ler e escrever, quando postos diante de situações discursivas ${ }^{10}$ que requerem compreensão dos enunciados, mesmo na língua que lhes é familiar, a materna.

Inseridos no Programa Institucional de Bolsa de Iniciação à Docência PIBID ${ }^{11}$, que tem como objetivo a valorização da formação de professores na

\footnotetext{
${ }^{10} 0$ termo situações discursivas se refere a quaisquer situações cotidianas nas quais os indivíduos entrem em contato com os diferentes discursos (orais ou escritos) nas esferas sociais e educativas.

1. ano de 2014. Este artigo retrata a primeira aplicação do Projeto PLAI.
}

educação básica, reuniram-se, no ano de 2014, uma professora de inglês de uma universidade estadual, uma professora de inglês de uma escola pública estadual e cinco acadêmicos do Curso de Letras Português/Inglês, motivados a produzir um projeto que incentivasse a leitura dos alunos de inglês do Ensino Fundamental e, ao mesmo tempo, buscasse a excelência nas práticas pedagógicas. Com esse objetivo, o grupo buscou estratégias para conduzir da melhor forma possível a dinâmica do projeto.

O projeto PLAI foi planejado em encontros presenciais semanais no primeiro trimestre escolar do ano de 2014, nas dependências da Unioeste, e aplicado no segundo trimestre (um trimestre para observações e outro para as regências das aulas) em uma escola da rede pública estadual de ensino, em turmas de $6^{\circ}, 7^{\circ}$ e $8^{\circ}$ anos do ensino fundamental, cada turma com aproximadamente 30 alunos. Durante a execução, foram realizados acompanhamentos pela professora coordenadora e registros constantes pela professora supervisora (diário de supervisão) e pelos acadêmicos Pibidianos através de relatórios semanais.

Assim, o PLAI foi planejado com o intuito de enriquecer as práticas de ensino da língua inglesa no contexto público da rede estadual de ensino, tornando à aprendizagem significativa aos alunos. Nesse delineamento, esperava-se que, ao proporcionar aos alunos condições favoráveis à aprendizagem de inglês, estes enriquecessem, também, suas relações com a utilização da língua materna. A partir destes enfoques, o de contribuir para o interesse pela leitura e o de motivar os alunos ao aprendizado de um idioma de repercussão internacional, o escopo do projeto foi delineado.

A abordagem que delineia o projeto PLAI é denominada de Literamento por entender a Literatura como uma fonte rica de acesso ao Letramento dos alunos quando integrada aos estudos linguísticos, tecnológicos, midiáticos e cinematográficos. Nesse escopo, para incentivar os alunos à leitura, o projeto elencou a literatura de obras clássicas e contemporâneas nas aulas de 
inglês, visando ao mesmo tempo, motivá-los para a aprendizagem de inglês. Dentre as variadas maneiras de abordar o ensino de inglês e a leitura, com o intuito de tornar o processo de ensino significativo, o grupo selecionou as seguintes formas de atuação: 1) o uso de tecnologias midiáticas (cinema, vídeos, músicas) para a inovação das atividades de ensino; 2) o uso de textos literários integrado às tecnologias para despertar o interesse dos alunos pela leitura e pelo idioma; 3) a elaboração de material didático exclusivo de apoio; 4) a interdisciplinaridade com outras áreas do conhecimento (educação física e artes).

Como aporte teórico multifacetado, o PLAI se respaldou nos estudos que entendem que um projeto de letramento deve estar "intimamente ligado a modos culturais de usar a linguagem” (BRASIL, 2006, p. 98), englobando as concepções de discurso, letramento e poder (FOUCAULT, 1996; FREIRE, 2005); as abordagens sociodiscursivas para o ensino de línguas (BAKHTIN, 1999); os estudos do Inglês como uma Língua Franca Global (CRYSTAL, 2003; JENKINS, 2007; PALLU, 2013); e também, nos documentos oficiais para o ensino de inglês (PARANÁ, 2008; BRASIL, 2006).

A conjunção destes estudos objetivou construir um projeto que contemplasse a leitura nas aulas de inglês, voltado para a significação social da aprendizagem, considerando-se os seguintes pressupostos:

0 projeto de letramento pode coadunar-se com a proposta de inclusão digital e social e atender a um propósito educacional, pois possibilita o desenvolvimento do senso de cidadania. 0 projeto prevê trabalhar a linguagem (em língua materna e em línguas estrangeiras) desenvolvendo os modos culturais de ver, descrever, explicar. No que concerne à leitura, contempla pedagogicamente suas várias modalidades: a visual (mídia, cinema), a informática (digital), a multicultural e a crítica (presente em todas as modalidades). Procura desenvolver um leitor como aquele que entende que aquilo que lê é uma representação textual, como aquele que diante do que lê, assume uma posição ou relação epistemológica no que concerne a valores, ideologias, discursos, visão de mundo. (BRASIL, 2006, p. 98).
Assim, visando a atender ao propósito educacional de explorar o inglês de maneira a despertar nos alunos o interesse pelos conteúdos e motiválos ao trabalho proposto pelo projeto, após a observação do contexto de aprendizagem dos alunos na escola, o grupo estabeleceu como critério de escolha das obras literárias a serem trabalhadas, três premissas: 1) obras clássicas e também contemporâneas para diversificação de gêneros; 2) obras literárias clássicas que já fossem de conhecimento prévio dos alunos - por isso a escolha recaiu nos contos de Hans Christian Andersen -; 3) obras literárias contemporâneas - contemplando a saga Harry Potter.

Para explorar os conteúdos literários e linguísticos e priorizar o ensino de inglês nas aulas, o grupo produziu um Caderno de Literamento de Inglês, escrito em inglês, tendo como embasamento teórico as concepções discursivas (BAKHTIN, 2003; MEURER, 2005); dos estudos do fenômeno do Inglês como uma Língua Franca Global (CRYSTAL, 2013; JENKINS, 2008; PALLU, 2013); e dos estudos literários (BLOOM, 2001; LAZAR, 2005; BURGESS, 2006). O Caderno Literamento contém todo o material literário e linguístico enriquecido pelo uso da tecnologia midiática (vídeos, filmes, músicas, jogos, imagens, etc.) e pelos aparatos tecnológicos como multimídia, computador, televisão, celulares, etc.

Assim, para percepção da relevância dos textos literários escolhidos, alguns elementos que compõem o perfil dos alunos foram observados para composição do Caderno, dentre eles: aspectos culturais, idade, maturidade intelectual, entendimento emocional e nível linguístico (LAZAR, 2005). A escolha das obras visou a favorecer a participação dos alunos pelo fato de representar um universo literário que lhes é familiar. O Caderno Literamento foi constituído em duas partes com um total de 18 aulas: 09 unidades trabalhando os contos dos Irmãos Grimm para as turmas de 6으 e 7음 anos e 09 unidades sobre Harry Potter para as turmas de $8^{\circ}$ ano, da seguinte maneira: 


\section{Parte 1: Grimm brothers' tales}

Class 1 - Grimm Brothers' Biography

Class 2 - Introducing Little Red Riding Hood Tale

Class 3 - Red Riding Hood Tale Bricollage

Class 4 - Cinderella Tale around the World

Class 5 - Introducing Cinderella Tale

Class 6 - Cinderella Video

Class 7 - Snow White Tale video

Class 8 - Introducing Snow White Tale

Class 9 - Snow White Tale Activities.

\section{Parte 2: Harry Potter}

Class 1 - J. K. Rowling

Class 2 - Harry Potter's Books

Class 3 - Harry Potter's Main Characters

Class 4 - Harry Potter and the Sorcerer's Stone Book

Class 5 - Harry Potter and the Sorcerer's Stone Movie

Class 6 - Harry Potter and Hogwarts

Class 7 - Harry Potter and the Movie Adaptations

Class 8 - Harry Potter and the Quidditch

Class 9 - Harry Potter and the Movie Adaptations

Cada unidade (class) do Caderno Literamento foi subdividida em três momentos: introduction, development e closing, utilizando atividades adequadas à temática de cada aula (atividades de compreensão, atividades linguísticas, utilização de imagens, vídeos, extratos de filmes, música, jogos, etc.) e considerando o perfil de cada série. Ao planejar, elaborar e aplicar o Caderno Literamento, o grupo manteve o objetivo de priorizar o ensino e a aprendizagem da língua-alvo e a autonomia no processo da leitura e, para tanto, todas as atividades do livro levaram em consideração o preparo prévio dos alunos para a realização das atividades, oportunizando e maximizando o desenvolvimento vocabular necessário para a produção dos conhecimentos de leitura, interpretação e reflexão. Esta maneira de entender o processo de leitura pode ser visualizada nas palavras de Machado (2002) quando explica que:

A reflexão que estamos propondo insere-se justamente nessa perspectiva: fornecer elementos ao aluno que o levem a refletir sobre o texto literário e o texto fílmico, promovendo a busca consciente da produção de sentido e o desenvolvimento de suas próprias estratégias de leitura. Não se trata de condicioná-lo, nem fornecer um modelo para, através de uma espécie de treinamento, adestra-lo na análise textual (MACHADO, 2002, p. 128).

Ao final da aplicação, foi solicitado aos Pibidianos (códigos PLAIP1 à PLAIP5) um relato escrito de sua percepção sobre a utilização das tecnologias no PLAI e, também, entregue aos alunos um questionário para a avaliação dos rendimentos nas questões relacionadas à metodologia adotada, à percepção da aprendizagem de inglês e da contribuição do próprio aluno às atividades realizadas, bem como os pontos negativos e positivos e sugestões. Do total de questionários entregues aos alunos, aproximadamente noventa, foram devolvidos 72 (sob códigos PLAI1 a PLAI72).

\section{Os resultados obtidos}

O PLAI se constituiu um projeto multifacetado com o objetivo de contribuir para a formação dos professores de inglês visando seu fortalecimento para a tarefa dupla de motivar os alunos ao aprendizado do idioma e, também, incentivá-los às leituras. Diante desta proposta, os Pibidianos participantes se engajaram em várias atividades num movimento constante de encontros, tanto na universidade quanto na escola participante. 
Primeiramente, para visualizar alguns dos resultados alcançados na questão da contribuição geral para a formação dos Pibidianos, reportamonos ao conjunto das cinco competências (apresentadas anteriormente neste texto) que foram exploradas no PLAI visando contribuir para o letramento crítico digital desses professores em formação, quais sejam: a competência computacional; a competência comunicacional; a competência multimídia; a competência informacional; e a competência linguística.

A competência computacional foi praticada em diversos momentos pelo grupo, nos quais todos tiveram oportunidades de utilizar a tecnologia no preparo de materiais, nas aulas práticas na escola, nos eventos em que participaram e nos grupos de estudos realizados nos laboratórios de informática da escola e da universidade. Para os acadêmicos Pibidianos, o fato de poder utilizar pedagogicamente os recursos tecnológicos lhes ofereceu um treinamento que, muitas vezes, não é possível durante o curso de graduação. Além disso, a experiência de utilização das tecnologias nas regências de aulas, nas quais os imprevistos devem estar acompanhados de estratégias metodológicas para correção de falhas, foi efetiva. Como o grupo do projeto PLAI contou com diferentes níveis de conhecimento das novas tecnologias e com afinidades também diferenciadas, foi possível explorar as facilidades e dificuldades de todos para o alcance dos resultados esperados e um aprimoramento geral do projeto, considerando-se a proposta de utilização das tecnologias no desenvolvimento e execução das atividades de ensino.

A competência comunicacional possibilitou ao grupo se comunicar de forma rápida nos momentos não presenciais através do uso das mídias tecnológicas das redes sociais pelo website Facebook e pelo aplicativo WhatsApp. Esta competência também favoreceu o acompanhamento da coordenadora do PLAI, professora da Unioeste, nas atividades realizadas na escola imediatamente após a sua realização. 0 blog literamento exerceu a função de registrar as atividades realizadas, constituindo-se em uma ferramenta institucional para comprovação nos relatórios emitidos das atividades realizadas. A utilização de materiais pesquisados na web (textos, imagens, vídeos, músicas, documentários, biografias, etc.) contribuiu para o desenvolvimento das competências multimídia e informacional, mediante estudos, análises e escolhas nas quais todos os membros do grupo contribuíam com seus conhecimentos e habilidades específicas e também suas dificuldades individuais.

Estas quatro competências foram agregadas à competência linguística, ou seja, ao domínio do conhecimento específico (língua inglesa) necessário para que o professor de inglês atue de forma mais segura e construa sua própria metodologia de ensino. Embora em muitos momentos esta competência tenha sido incentivada e aprimorada no projeto, é válido destacar que ainda há muito que se acrescentar para que os professores de inglês tenham maior domínio no idioma, além do enriquecimento constante da prática pedagógica. Contudo, ao vivenciar a prática em sala de aula, os acadêmicos puderam constatar os desafios que o professor de inglês enfrenta em seu cotidiano escolar. Neste sentido, está prevista uma maior ênfase na utilização de inglês para os próximos períodos de atuação do subprojeto PIBID Letras/ Inglês, nos momentos de planejamentos e encontros do grupo e não somente nas regências de aulas na escola.

Todas as competências integradas tiveram o auxílio e participação da professora coordenadora e da professora supervisora. Vale apontar que o relacionamento instaurado de renovação das práticas pedagógicas foi contemplado, possibilitando aos acadêmicos e professores compartilhar suas experiências para o enriquecimento mútuo. Composto por diferentes subjetividades, o PLAI compõe um espaço de respeito às múltiplas identidades e de abertura a inovações para a construção de conhecimentos multifacetados. 
Estes resultados podem ser demonstrados nos relatos escritos produzido pelos Pibidianos ao final da execução do PLAI, conforme o relato de um deles (PLAIP2), abaixo transcrito em sua íntegra:

\section{"O PIBID e o uso de tecnologias}

O uso de tecnologias está presente na vida dos nossos alunos diariamente, seja para pesquisa ou para entretenimento. Nós, como Pibidianos, portanto futuros professores, temos de estar em harmonia com esses recursos e saber seus benefícios na prática docente.

No projeto PLAI utilizamos a rede social Facebook para comunicação diária entre Pibidianos e professores, facilitando o contato e divulgação dos relatórios, bem como uma escala de idas à escola. Dessa forma, rápida e informal, é possível estar ciente de tudo que acontece durante a permanência do acadêmico na escola e programar a pauta para a reunião semanal que ocorre na Universidade.

Além do Facebook, outro meio de interação é o blog do PIBID, local de publicação de fotos e ações praticadas pelo grupo, como um fichário sobre todas as atividades promovidas. Temos também, como meio de comunicação, o aplicativo para celular Whatsapp, para os momentos de recados breves e informes urgentes, sendo de fácil acesso e checagem constante.

Com o crescimento constante da tecnologia, atrelamos a ela algumas atividades do PIBID em sala de aula. Nosso subprojeto trabalhou com o conceito de Literamento (PALLU, 2012), o qual envolve o letramento e a literatura no ensino de Língua Inglesa, levando para os alunos um material didático por nós produzido com enfoque em Harry Potter e clássicos dos Irmãos Grimm

Na escola participante temos acesso ao multimídia, pelo qual passamos filmes e pequenos vídeos pertinentes à aula planejada pelos Pibidianos, bem como utilizamos a TV pendrive presente em todas as salas para a reprodução de músicas e imagens. Em momentos oportunos, os alunos foram levados ao laboratório de informática para pesquisa e acesso ao Blog do PIBID, para conferirem as fotos em que aparecem.

0 resultado desse vínculo entre a prática docente e a tecnologia tem se mostrado positivo, pois nos auxilia a pensar formas de chamar a atenção dos nossos alunos fazendo com que se interessem pelo conteúdo, e que também aprendam a explorar a tecnologia a seu favor." (PLAIP2)
Em relação aos resultados alcançados quanto à motivação para aprender inglês, os dados obtidos pelos questionários demonstraram-se favoráveis ao Projeto. Quando indagados se o Projeto PLAI fez com que o aprendizado de inglês se tornasse mais interessante, do total de 72 questionários (codificados como PLAI1 a PLAI66), foram obtidos os seguintes resultados: 59 respostas positivas; 05 alunos não responderam à questão; 02 foram negativas e 02 alunos responderam que parcialmente. Considerando a importância de promover a reflexão de todos os participantes envolvidos no projeto, os dados permitiram, ainda, perceber as impressões dos próprios alunos sobre o projeto em relação à metodologia empregada, a contribuição do mesmo, os pontos positivos e negativos e a auto avaliação dos próprios alunos sobre suas participações.

De acordo com as respostas obtidas em relação à metodologia adotada, quando questionados se o método literamento (língua inglesa a partir da literatura) havia contribuído para o aprendizado de inglês, as respostas enfatizaram os seguintes aspectos: 1) a motivação geral dos alunos para aprender inglês justificada pelas atividades diferenciadas, pelo uso de tecnologia e, também, pelo material próprio e diferente do livro didático; 2) o interesse despertado pela aprendizagem devido à constituição de aulas mais interessantes; 3) o conteúdo literário que lhes é familiar favoreceu a aprendizagem; 4) o apreço à utilização da literatura nas aulas de inglês; 5) uma maior concentração durante as atividades de leitura e escrita; 7) uma maior aquisição de vocabulário; 6) a facilidade com o inglês sentida pela metodologia diferenciada de ensino.

Estes resultados podem ser visualizados pelas respostas dos alunos, nos extratos abaixo transcritos:

"Todos ficaram entretidos com a literatura." (PLAI60)

"Ficar sempre no livro didático enjoa e a gente começa a ter menos interesse, com as histórias e os vídeos ficou mais divertido aprender inglês." (PLAI46) 
“Com a literatura o estudo fica mais fácil." (PLAI46)

"Aprendi mais como falar, pronunciar as palavras." (PLAI33)

“Por ser diferente, assim nós nos interessamos mais na língua inglesa." (PLAI12) "Aprender a ler e escrever em inglês e com as brincadeiras divertidas e etc. muitas coisas divertidas." (PLAI13)

"Porque os contos aprendidos são contos populares, contos que a gente já conhecia e estuda-los em inglês foi interessante." (PLAI41)

Referente à avaliação da autoaprendizagem, os alunos foram indagados acerca dos aspectos que poderiam ser aprimorados em relação à sua participação em sala de aula. Pelas respostas, foi possível perceber os seguintes posicionamentos: 1) queixa de indisciplina dos próprios alunos e da falta de controle de classe dos acadêmicos; 2) solicitação de paciência dos acadêmicos Pibidianos com os alunos; 3) conscientização de que os alunos poderiam ter se dedicado mais ao projeto; 4) falta de experiência dos acadêmicos Pibidianos.

"Foi tudo muito legal. Gostei de tudo, mas em relação aos meus colegas poderiam colaborar mais. Peço desculpas pela bagunça em nome da classe." (PLAI46)

"O bom foi que os professores tinham muita vontade que a gente aprendesse e nos explicavam muito bem as questões. $O$ ruim foi que eles não conseguiam controlar muito bem a sala." (PLAI28)

"Adorei as atividades. Mas eles não explicam tão bem quanto os professores profissionais." (PLAI38)

"Eu gostei de tudo. Só acho que nas horas de explicar eles poderiam melhorar. Porque eu ficava meio confusa." (PLAI47)

Para o processo de auto avaliação geral do Projeto, foi solicitado aos alunos que apontassem os pontos positivos e negativos do PLAI e também, que fornecessem sugestões ou críticas. Os dados evidenciaram o que segue: 1) desejo pela continuidade da aplicação do projeto nos anos seguintes de aprendizagem; 2) solicitação de trabalhos com músicas, como sugestão para próximos trabalhos; 3) interesse pelo material do Caderno Literamento; 6) dedicação dos professores Pibidianos às aulas; como demonstram os relatos abaixo transcritos:

"Ter mais páginas na apostila." (PLAI24)

"Com esse aprendizado foi 100\%, além de aprender eu me diverti muito."(PLAI13) "A aprendizagem foi muito boa, conseguimos aprender melhor. Não houve nenhum ponto negativo." (PLAI12)

"Bom eu até agora não vi nenhum ponto negativo. Eles (as) nos deram um ótimo ensino, trabalharam coisas novas e eu gosto disso." (PLAI14)

"A aprendizagem foi muito boa conseguimos aprender melhor. Não houve nenhum ponto negativo." (PLAI12)

"Quando começou a ter o Projeto PIBID aqui na escola os estudos de inglês passaram a ser mais legais." (PLAI40)

"Poderia ter mais filmes mais jogos, e com as críticas nenhuma." (PLAI4)

Por fim, além do acompanhamento constante da professora coordenadora do PLAI na universidade, houve também o monitoramento da supervisora na escola (com registros em um diário), acompanhado de discussões nos encontros com todos os componentes do grupo para avaliação dos resultados. Esse movimento objetivava a constante reformulação das estratégias pedagógicas, visando alcançar melhores resultados. Nos registros da professora supervisora, foram apontados os avanços e as dificuldades dos acadêmicos na condução das aulas de regência, que se efetivaram mediante a aplicação do Caderno de Literamento de Inglês com o aporte tecnológico. Os principais pontos observados pela supervisora nos registros foram compilados pela professora coordenadora do PLAI. Os resultados evidenciaram os seguintes aspectos referentes à aplicação do PLAI: 1) motivação dos acadêmicos pela participação do projeto; 2) importância do PLAI para a aproximação da teoria e da prática; 3) efetivação da práxis pedagógica diante desta integração; 4) dificuldades no 
início das regências quanto ao domínio de classe; 5) obstáculos para a plena utilização da tecnologia na escola pública (falta de local apropriado; falta de equipamentos; por exemplo); 6) esforços para a utilização da tecnologia midiática nas aulas diante desses obstáculos; 7) dificuldade em administrar a disciplina em sala de aula diante das turmas heterogêneas e com grande número de alunos; 8) dificuldades psicopedagógicas para trabalhar com os alunos oriundos do processo de inclusão; 9) importância do material didático de apoio próprio; 10) enriquecimento da formação inicial docente dos acadêmicos participantes; 11) participação mais efetiva dos alunos nas leituras com a aplicação do Projeto PLAI.

\section{Conclusão}

O letramento dos sujeitos, em todas as esferas sociais e educativas, representa um grande desafio à educação brasileira. Diante da realidade socioeconômica do país, esta tarefa se torna ainda mais desafiadora e complexa. Este artigo, como explanado na seção teórica, entende a questão do letramento crítico digital como fonte de contribuição para a formação de professores de inglês e para atuação efetiva na formação de leitores.

Cientes da fusão de conhecimentos que o letramento crítico digital engloba e de que a ação na formação de leitores requer, além de um aprofundamento teórico sólido - investimentos não somente de tempo, como também de espaço - o Projeto Literamento nas Aulas de Inglês (PLAI), subsidiado pelo PIBID foi o local reivindicado e conquistado para a efetivação criteriosa desta temática, haja vista a grande oportunidade aberta para o fortalecimento da formação de professores em todos os projetos deste programa nacional. $\mathrm{O}$ contexto que integra a formação de professores e a educação fundamental foi eleito, nesta proposta, como um espaço fértil para o fomento de trabalhos que visem à melhoria dos sujeitos diante do consumo e da produção de textos variados, pois sem a apropriação adequada dos discursos informados pelas linguagens, os resultados têm se mostrado extremamente desfavoráveis nas tomadas de decisões que se apresentam nas diferentes fases da vida dos cidadãos brasileiros.

O PLAI buscou construir uma metodologia que tornasse significativo o ensino e aprendizagem de inglês, tanto aos professores quanto aos alunos da escola pública, acreditando que, mediante esta significação a formação de alunos leitores é uma realidade possível. Vale ressaltar que diante de todas as dificuldades presentes neste contexto de ensino, o grupo de participantes do projeto estudou, analisou e buscou condições e estratégias para alcançar os objetivos almejados. Desta forma, a formação de leitores foi considerada um dos espaços para investimentos de novas abordagens e de futuros professores dispostos a enriquecê-la e as aulas de inglês representaram o local de produção de conhecimentos para despertar o interesse dos alunos.

O projeto oportunizou várias atividades pedagógicas desenvolvidas em um movimento de integração entre escola e universidade. Dentre elas encontram-se: grupos de estudos em encontros semanais na universidade; aulas de observação do contexto escolar; aulas de regências com o uso de recursos tecnológicos na escola; além de palestras; visitas de alunos da escola na universidade; interdisciplinaridade com os professores de educação física; produção de materiais didáticos e, também, a participação dos Pibidianos em eventos científicos externos para apresentação dos trabalhos realizados.

Considerando que o fator tempo na educação é moroso quando se refere aos avanços efetivados, podemos afirmar que todo o período dedicado pelo PLAI representa uma contribuição dentre todas as possíveis para a questão da formação de leitores em nosso país, a qual merece constante dedicação para sua melhoria. Contudo, a estratégia adotada para atingir resultados em uma ampla temática como a do letramento, nesta experiência, foi a integração 
do projeto aos trabalhos da formação inicial e continuada dos professores de inglês. Este pensamento foi norteado levando em consideração a premissa de que para que os alunos sejam motivados à leitura, é necessário que seus professores estejam preparados para uma condução efetiva deste conhecimento.

Assim, diante dos resultados positivos e também negativos relatados neste artigo, a grande contribuição alcançada nesta experiência tem sido evidenciada, primeiramente, na tarefa bem-sucedida de auxiliar os professores da área do ensino de línguas estrangeiras a conduzirem suas atuações para contribuir para o letramento nas aulas de inglês, tornando-as cada vez mais próximas dos interesses e usos dos alunos.

Considerando que vivemos num mundo cada vez mais globalizado no qual não conseguimos mais isolar o que acontece fora das salas de aulas das práticas educativas, tornar o ensino e aprendizagem significativos, não somente aos alunos como também aos professores, representa, na atualidade, uma fonte para investimentos nas políticas públicas da educação. Neste sentido, o Programa Institucional de Bolsa de Iniciação à Docência (PIBID) representa uma grande oportunidade para diferentes esferas de licenciaturas.

\section{Referências}

BAKHTIN, Mikhail. Estética da criação verbal. 4. ed. São Paulo: Martins Pontes, 2003.

BLOOM, Harold. How to read and why. New York: Touchstone, 2001.

BRASIL, Secretaria da educação básica. Linguagens, códigos e suas tecnologias. Brasília, 2006. 239 p. (Orientações curriculares para o ensino médio, 1).

BRITO, Glaucia da Silva. Educação e novas tecnologias: um re-pensar. 2. ed. Curitiba: Ibpex, 2008.

BURGESS, Antony. A literatura inglesa. Tradução de Duda Machado. 2. ed. São Paulo: Ática, 2006.
CANI, Josiane Brunetti. Letramento digital: competências e habilidades para navegação em rede. Universidade, EAD e Software Livre. 2015. Lab SEMIOTEC/FALE/UFMG Disponível em: <http://ueadsl.textolivre.pro.br/2015.1/papers/upload/54.pdf>. Acesso em: 14 fev. 2016.

CRYSTAL, David. English as a global language. New York: Cambrige University Press, 2013.

DIAS, Reinildes. A incorporação de estratégias ao ensino aprendizagem de leitura em inglês como língua estrangeira. In: PAIVA, V. L. O de. M. (Org.). Ensino de língua inglesa: reflexões e experiências. 3. ed. Campinas, SP: Pontes, 2005.

EL KADRI, Michele. Inglês como língua franca: atitudes de formadores de professores. In: GIMENEZ, Telma (Org.) et al. Inglês como língua franca: ensino, aprendizagem e formação de professores. Campinas, SP: Pontes, 2011. p. 163-192.

FREIRE, Paulo. A importância do ato de ler. Em três artigos que se completam. 37. ed. São Paulo: Cortez, 1992.

FREITAS, Maria T. Letramento digital e formação de professores. Educação em Revista. Belo Horizonte, v. 26, n. 3, p. 335-352, dez. 2010.

FOCAULT, Michel. A ordem do discurso. São Paulo: Edições Loyola, 1996.

JENKINS, Jennifer. English as a língua franca. University of Southampton, JACET 47th Anual convention, Waseda University, 11-13 Sept. 2008.

JORDÃO, Clarissa Menezes de. As Lentes do Discurso. Letramento e criticidade no mundo digital, Campinas, v. 46, n. 1, p. 19-29, jan.-jun. 2007.

KLEIMAN, Ângela. O conceito de letramento e suas implicações para a alfabetização. Projeto Letramento Temático do Professor. Unicamp. 2016. Disponível em: <http://www. letramento.iel.unicamp.br/publicacoes/artigos/Letramento_AngelaKleiman.pdf >. Acesso em: 11 jul. 2016.

LAZER, Gillian. Literature and language teaching. A guide for teachers and trainers Cambridge University Press, Cambridge, UK, 2005.

MACHADO, Maristela Gonçalves Sousa. Do texto literário ao texto fílmico: uma reflexão sobre a formação de leitores autônomos. In: NICOLAIDES, C. et al. $O$ desenvolvimento da autonomia no ambiente de aprendizagem de línguas estrangeiras. Fórum internacional de línguas estrangeiras. Pelotas: UFPEL: UCPEL, 2003.

MARTINEZ, Juliana Zeggio. Uma leitura sobre concepções de linguagem e educação profissional de professores de língua inglesa. 2007. 154f. Dissertação (Mestrado) Programa de Pós-graduação em Letras, Universidade Federal do Paraná, 2007. 
MEURER, José Luiz. Gêneros textuais na análise crítica de Fairglough. In: MEURER, J. L.; BONINI, A.; MOTTA-ROTH, D. (Eds.). Gêneros: teorias, métodos, debates. São Paulo: Parábola Editorial, 2005. p. 81-106.

PALLU, Nelza Mara. Literatura inglesa: uma abordagem integrada ao ensino de inglês. In: JORNADA DE ESTUDOS LINGUÍSTICOS E LITERÁRIOS, 15., 2012, Marechal Cândido Rondon.

Que inglês utilizamos e ensinamos? Reinterpretações de professores de inglês sobre o processo de ensino e aprendizagem do inglês contemporâneo. 2013. 242f. Tese (Doutorado em Letras) - Universidade Federal do Paraná, 2013.

PARANÁ, Secretaria de Estado da Educação Básica do Paraná. Diretrizes Curriculares da Educação Básica: língua estrangeira moderna. Curitiba, 2008.

PIMENTA, Sônia Maria de Oliveira. Os efeitos de distanciamento na leitura crítica de textos. In: NICOLAIDES, C. et al. $O$ desenvolvimento da autonomia no ambiente de aprendizagem de línguas estrangeiras. Fórum internacional de línguas estrangeiras. Pelotas: UFPEL/UCPEL, 2003.

SANTAELLA, Lúcia. Da cultura das mídias à cibercultura: o advento do pós-humano. Revista FAMECOS, Porto Alegre, n. 22, p. 23-32, dez. 2003.

SILVA, Monica Ribeiro da; COLONTONIO, Eloise Médice. As Diretrizes Curriculares Nacionais para o Ensino Médio e as proposições sobre trabalho, ciência, tecnologia e cultura: reflexões necessárias. Revista Brasileira de Educação, v. 19, n. 58 jul.-set. 2014.

SOUZA, Lynn Mario Trindade Menezes de. O professor de inglês e os letramentos no século XXI: métodos ou ética? In: JORDÃO, Clarissa Menezes (Orgs.). Formação "desformatada": práticas de professores de língua inglesa. Novas perspectivas em linguística aplicada. Campinas, SP: Pontes, 2011. Vol. 15.

Recebido em 03/04/2016.

Aceito em 29/08/2016. 